Myasthenia gravis with thymoma and pure red blood cell aplasia. Am $\mathcal{F}$ Clin Pathol 1988;89:687-93.

4 Loughran TP Jr, Starkebaum G. Large granular lymphocyte leukaemia. Report of 38 cases and review of the literature. Medicine (Balt) 1987;66:397-405.

5 Anonymous. Large granular lymphocytic leukaemia [editorial]. Lancet 1991;338:284-5.

6 Masaoka A, Hashimoto T, Shibata K, Yamakawa Y, Nakamae K, Ilzuka $M$. Thymomas associated with pure red cell aplasia. Histological and follow-up studies. Cancer, 1989;64:1872-8.

7 Starkebaum G, Loughran TP Jr, Kalyanaraman VS Kadin ME, Kidd PG, Singer JW, et al. Serum reactivity to HTLV-1 proteins in patients with large granular lymto HTLV-1 proteins in patients with large

8 Levitt LJ, Reyes GR, Moonka DK, Bensch K, Miller RA, Englemann EG. Human T cell leukaemia virus-1-associated T-suppressor cell inhibition of erythropoiesis in a patient with pure red cell aplasia and chronic $T$ gammalymphoproliferative disease. $f$ Clin Invest 1988;81: 538-48.

9 Ono A, Saito H, Kondo S, Yoshimatsu H, Tsuchiya M. RNA tumour virus in human thymomas and thymus hyperplasias. Semin Surg Oncol 1985;1:139-52.

10 Nidorf D, Saleem A. Immunosuppressive mechanisms in pure red cell aplasia-a review. Ann Clin Lab $S_{c i}$ 1990;20:214-19.

11 Murphy MF, Izaguirre CA, Dhaliwal H, Wrigley PFM, Waters AH. Pure red cell aplasia-evidence for an inhibitory action of the bone marrow adherent cell layer. inhibitory action of the bone marr

12 Vie H, Chevalier S, Gerand R, Moisan JP, Praloran V, Devilder MC, et al. Clonal expansion of lymphocytes bearing the $\gamma \delta \mathrm{T}$-cell receptor in a patient with large granular lymphocyte disorder. Blood 1989;74:285-90.

\title{
Concealed homicidal strangulation first discovered at necropsy
}

\author{
D W Sadler
}

\begin{abstract}
One adult and one childhood case of concealed homicide by strangulation are presented. Both cases were first recognised on formal neck dissection at necropsy. Neither showed any obvious external trauma to the neck or laryngeal fracture. External petechiae were absent in the child. The pattern of internal injuries in both cases suggested that the likely mechanism was strangulation. Particular care is required in busy routine medicolegal practice in order to detect deaths which are not immediately apparent as asphyxial.
\end{abstract}

$(F$ Clin Pathol 1994;47:679-680)

\section{Case reports}

CASE 1

The body of a 33 year old man was found lying face down on a country track. Although the first police officer on the scene had been concerned, the consensus view of CID officers and the police surgeon, after examining the body, both at the locus and stripped of clothing at the police mortuary, was of sudden natural death. The case was referred for routine medicolegal necropsy the following day. Occasional minor fresh abrasions were present on the forehead and elbows. There was a $4 \times 1 \mathrm{~mm}$ laceration to the frenulum of the upper lip. There were florid petechiae over the eyelids and conjunctivae. There were no externally apparent neck injuries. Neck dissection revealed bruising in the left platysma, sternomastoid, omohyoid and sternohyoid muscles, in both inferior pharyngeal constrictor muscles overlying the superior horns of the thyroid cartilage and over the upper right carotid sheath. The thyroid cartilage and hyoid bone were intact. There were florid mucosal haemorrhages, ranging from
1-7 mm, over the lateral and anterior walls of the oropharynx and posterior surface of the epiglottis. On the right edge of the tongue was an area of haemorrhage $8 \mathrm{~mm}$ in maximum dimension. Dissection of the back revealed fresh bruising within the back muscles, either side of T11 level and to the left of $\mathrm{L} 1$ level. No further trauma or any clinically relevant natural disease were identified at necropsy. Toxicological analyses were negative. The cause of death was given as "strangulation". After extensive police investigation and a Fatal Accident Inquiry the death is officially viewed as an unsolved homicide.

\section{CASE 2}

A 6 week old baby girl was found dead, lying face down on a couch after her mother was admitted to hospital for suspected self-poisoning. Suspicion of infanticide, rather than cot death, was raised when the mother recovered completely shortly after hospital admission. The child was well nourished and showed no external trauma. There was an abundant plume of yellow froth at the nostrils. There were no external petechiae. There were occasional petechiae over the visceral pleura, epicardium, and thymus. Neck dissection revealed two discrete areas of soft tissue bruising to the left upper neck, extending deeply around the digastric muscle and adjacent lymph nodes and becoming confluent over the carotid sheath and precervical fascia. Closer examination of the overlying skin revealed a bearly discernible $6 \mathrm{~mm}$ linear abrasion which became more obvious with drying over the next 24 hours. Dissection of the back of the neck revealed a $17 \times 13 \mathrm{~mm}$ horizontally aligned bruise straddling the midline within the upper trapezius muscle, $18 \mathrm{~mm}$ below the external occipital protruberance. No further trauma or natural disease was identified.

Microbiological screening and radiological 
skeletal survey, according to an exhaustive cot death protocol, were entirely negative. The cause of death was given as "mechanical asphyxiation". The mother admitted manual strangulation and was found guilty of culpable homicide on the grounds of diminished responsibility.

\section{Discussion}

Although the circumstances in both the cases presented gave rise to some suspicion, strangulation was not expected in either case. The adult showed florid facial and conjunctival petechiae, whereas the child showed none. Neither case showed any obvious external injury to the neck. In both cases strangulation was diagnosed on the basis of deep soft tissue bruising first apparent on in situ dissection of the neck structures at the end of the necropsy. In situ neck dissection, after removal of the brain and chest organs, avoids postmortem artefactual haemorrhage caused during dissection. ${ }^{12}$ Neither case showed any laryngeal fractures. This is not unexpected as fractures of the hyoid bone and thyroid cartilage are rare in young strangulation victims due to the elasticity of the unossified structures. ${ }^{3}$

The so-called "classic" general signs of asphyxia (petechiae, cyanosis, congestion and oedema) are typically most florid in the face and conjunctivae in cases of manual and ligature strangulation due to raised venous pressure and stagnation above the level of neck compression. ${ }^{45}$ Unfortunately, petechiae are also commonly seen in many non-asphyxial deaths due to increased venous pressure by terminal right heart failure ${ }^{6}$ or from attempted resuscitation. ${ }^{8}$ Petechiae are rarely seen in infants and young children even in cases of well documented asphyxiation and are absent in many adult suffocation deaths. ${ }^{5}$ Internal petechiae are of no diagnostic relevance. ${ }^{4}$ Acute pulmonary oedema may result from acute upper airway obstruction, ${ }^{8}$ but is also a common terminal event in many non-asphyxial deaths. Thus the general signs of asphyxia are relatively non-specific and have been scathingly referred to by Adelson as the "obsolete diagnostic quintet". ${ }^{5}$ Although the presence of bruising and abrasions on the neck arouses suspicion of homicide, such injuries may also result from attempted resuscitation. Crescentric fingernail abrasions around the lower jaw, mouth and cheeks, and injuries to the buccal mucosa are typically described as artefacts of resuscitation. ${ }^{9}$

The main point of interest in the two cases presented is the absence of obvious external neck injury. In strangulation, generally, there are three possible explanations for the absence of external injuries. Firstly, the use of a broad soft ligature or forearm when the force is applied over a wide area. Secondly, when a manual grip is held in one place without any shifting or reapplication, until the circulation ceases so that no extravasation will occur from the damaged vessels. ${ }^{10}$ Thirdly, when rapid death due to reflex cardiac arrest occurs, bruising will not have time to develop.

It was postulated that in case 1 strangulation had been done by means of a forearm hold. The relevant pathological findings in this case were: moderate bruising in the strap muscles; florid petechial haemorrhages in the eyes and pharyngeal mucosa; no laryngeal fracture; and the absence of external bruising. These findings are closely similar to those in many of Kornblum's series of 33 deaths attributed to bar-arm or carotid sleeper choke holds. ${ }^{1112}$ The presence of bruising within the back muscles raises the possibility of counter pressure bruising, perhaps from a knee in the back of the victim.

Case 2 represents manual strangulation. There was extensive soft tissue and intramuscular bruising to the left upper neck anteriorly and a single deep bruise posteriorly, in the absence of external bruising at either site. Strangulation could have been achieved by a fixed gripping of the neck with the fingers adducted and placed anteriorly and with the thumb placed posteriorly. In this way the child would be facing away from the assailant, raising the unprovable possibility that there was also an element of soft smothering achieved by pressing the face into the soft couch.

In view of the non-specific nature of the general asphyxial signs and the problems frequently encountered in interpreting external and internal neck trauma, the diagnosis of asphyxial death requires considerable caution. The scene, circumstances and history are therefore of great importance. With this information in mind, careful external examination followed by in situ dissection of the drained neck structures will resolve the issue in most dubious cases. In busy routine medicolegal practice, in some jurisdictions, the pathologist may be faced with an already eviscerated body, accompanied by scanty background information. Under these circumstances the potential exists for cases of subtle homicidal strangulation or smothering to pass unnoticed.

1 Prinsloo I, Gordon I. Post mortem artefacts of the neck: their differentiation from ante mortem bruises. South African Med f 1951;25:358-61.

2 Vanezis P. Post mortem techniques in the evaluation of neck injury. F Clin Pathol 1993;46:500-6.

3 O'Halloran RL, Lundy JK. Age and ossification of the hyoid bone: forensic implications. $\mathcal{F}$ Forens Sci 1987;32: 1655-9.

4 Vanezis P. Compressive neck injury 1: Signs of mechanical asphyxia. In: Pathology of neck injury. London: Butrerworths, 1989:44-50.

$5 \mathrm{Knight} \mathrm{B.} \mathrm{Suffocation} \mathrm{and} \mathrm{asphyxia.} \mathrm{In:} \mathrm{Forensic} \mathrm{pathology.}$ New York: Edward Arnold, 1991:319-33.

6 Rao VJ, Wetli CV. The forensic significance of conjunctival petechiae. Am f For Med Pathol 1988;9:32-4.

7 Hood I, Ryan D, Spitz WU. Resuscitation and petechiae. Am f For Med Pathol 1988;9:35-7.

8 Oswait CE, Gates GA, Holstrom FMG. Pulmonary oedema as a complication of acute airway obstruction. fAMA 1977;238:1833-5.

9 Harm T, Rajs J. Face and neck injuries due to resuscitaion versus throttling. For Sci Int 1983;23:109-16.

10 Camps FE, Hunt AC. Pressure on the neck. F For Med 1959;6:116-35.

11 Kornblum RN. Medical analysis of police choke holds and general neck trauma: Part 1. Trauma 1986;27:7-60.

12 Kornblum RN. Medical analysis of police choke holds and general neck trauma: Part 2. Trauma 1986;28:13-64. 